\title{
Variation in Transmission Efficiency Among Barley yellow dwarf virus-RMV Isolates and Clones of the Normally Inefficient Aphid Vector, Rhopalosiphum padi
}

\author{
E. Lucio-Zavaleta, D. M. Smith, and S. M. Gray
}

First and second authors: Department of Plant Pathology, Cornell University; and third author: USDA, ARS, Ithaca, NY 14853. Accepted for publication 4 May 2001.

\begin{abstract}
Lucio-Zavaleta, E., Smith, D. M., and Gray, S. M. 2001. Variation in transmission efficiency among Barley yellow dwarf virus-RMV isolates and clones of the normally inefficient aphid vector, Rhopalosiphum padi. Phytopathology 91:792-796.

The RMV strain of Barley yellow dwarf virus (BYDV-RMV) is an unassigned member of the Luteoviridae that causes barley yellow dwarf in various cereal crops. The virus is most efficiently vectored by the aphid Rhopalosiphum maidis, but can also be vectored with varying efficiency by $R$. padi and Schizaphis graminum. Field collections of alate aphids migrating into the emerging winter wheat crop in the fall of 1994 in central New York identified a high proportion of $R$. padi transmitting BYDV-RMV. This prompted a comparison of the BYDV-RMV isolates and the $R$. padi populations found in the field with type virus and aphid species maintained in the laboratory. A majority of the field isolates of BYDV-RMV were similar to each other and to the type BYDV-RMV

isolate in disease severity on oat and in transmission by the laboratorymaintained population of $R$. maidis and a field-collected population of $R$. maidis. However, several field populations of $R$. padi differed in their ability to transmit the various BYDV-RMV isolates. The transmission efficiency of the $R$. padi clones was increased if acquisition and inoculation feeding periods were allowed at higher temperatures. In addition, the transmission efficiency of BYDV-RMV was significantly influenced by the aphid that inoculated the virus source tissue. In general, BYDVRMV transmission by $R$. padi was higher when $R$. padi was the aphid that inoculated the source tissue than when $R$. maidis was the inoculating aphid. The magnitude of the change varied among virus isolates and $R$. padi clones. These results indicate that, under certain environmental conditions, $R$. padi can play a significant role in the epidemiology of BYDVRMV. This may be especially significant in regions where corn is a major source of virus and of aphids that can carry virus into a fall-planted wheat crop.
\end{abstract}

Barley yellow dwarf is the most widespread virus disease of cereal crops and causes significant economic losses in cultivated cereal crops and in pasturelands (20). The disease is caused by several aphid-transmitted viruses in the Luteoviridae collectively known as the Barley yellow dwarf viruses (BYDV) and the Cereal yellow dwarf viruses (CYDV). Six virus species that cause barley yellow dwarf disease are currently recognized: BYDV-PAV and BYDV-MAV are members of the genus Luteovirus; CYDV-RPV is a member of the genus Polerovirus; and BYDV-SGV, BYDVGPV, and BYDV-RMV have yet to be assigned to either genus (23). All of the virus species were initially differentiated based on the aphid vector that transmitted them most efficiently $(3,34,38)$. Currently, it is more common to identify field isolates by serological and molecular techniques $(21,30,35)$. However, the aphid transmission phenotype is the most important diagnostic characteristic in terms of the epidemiology of the disease and designing control strategies that target the vector.

In recent years, BYDV-RMV and BYDV-PAV have been the predominant viruses infecting the New York winter wheat crop (8). BYDV-PAV is reported to be vectored efficiently by several aphid species, whereas BYDV-RMV is reported to be vectored efficiently only by Rhopalosiphum maidis, and inefficiently by Schizaphis graminum and $R$. padi (34). Therefore, it was interesting when routine sampling of aphids in winter wheat during the fall of 1994 revealed that $R$. padi was the aphid most

Corresponding author: S. M. Gray; E-mail address: SMG3@cornell.edu

Publication no. P-2001-0601-01R

This article is in the public domain and not copyrightable. It may be freely reprinted with customary crediting of the source. The American Phytopathological Society, 2001. frequently associated with transmission of BYDV-RMV. The generalized transmission phenotype of BYDV-RMV isolates is based on virus isolates and aphid vectors that have been maintained in the laboratory for over 40 years (34). Thus, it was possible that the laboratory aphids and virus were not representative of what was present in the field. However, field isolates from other geographical areas have had similar aphid vector phenotypes to the New York isolate (BYDV-RMV-NY) $(18,24,48)$, i.e., $R$. maidis is always the efficient vector, but the transmission efficiency by Schizaphis graminum and $R$. padi can vary considerably $(2,15,36)$.

The BYDV-RMV isolates from various geographic locations have, with one exception (47), been detected using the available BYDV-RMV-specific polyclonal antisera; however, coat protein sequences indicate that considerable diversity exists within the BYDV-RMV serotype $(4,6)$. It is unknown which, if any, coat protein sequences influence the aphid transmission phenotype of BYDV-RMV.

Genetic variation also exists among aphids within a species, and this may be manifested as differences in ability to vector BYDV. Morphological and karyotype differences exist among $R$. maidis biotypes, and both traits have been associated with differences in transmission efficiency of BYDV-RMV $(2,42)$. Morphological characteristics were also used to distinguish among some $R$. padi biotypes. Abnormalities in wing veination were associated with a clone of $R$. padi that efficiently transmitted BYDV-RMV (36).

The goal of this study was to determine if BYDV-RMV isolates infecting cereal crops in New York were similar with respect to aphid transmission phenotype to each other and to the BYDVRMV-NY-type isolate. In addition, $R$. maidis and $R$. padi populations collected from different host plants and at different times 
were examined for differences in their ability to vector BYDVRMV. This information is required to understand the epidemiology of barley yellow dwarf in New York and to determine how representative the type virus isolates are to isolates causing disease in the field.

\section{MATERIALS AND METHODS}

Aphids. The New York laboratory-maintained clones of $R$. padi (Rp-L), R. maidis (Rm-L), Sitobion avenae (Sa-L), and Schizaphis graminum (Sg-L) are described in Power and Gray (26). Two additional $R$. padi populations were collected in Ithaca, NY: one from corn (Rp-C) in 1995, and one from wheat (Rp-W) in 1993. In addition, $R$. maidis (Rm-A) and $R$. padi (Rp-A) were collected from corn plants in Albion, NY, in 1995. Aphid colonies were started with several adults collected from the same leaf, which are likely to be siblings. Subsequently, all aphids were maintained on barley plants as described by Rochow (34).

Virus isolates. A history of the NY-BYDV isolates and their maintenance was reviewed by Power and Gray (26). Additional BYDV-RMV isolates were obtained from viruliferous alate aphids collected in the field. In 1994 and 1995, alate aphids alighting on winter wheat were collected in Ithaca and Aurora, NY. Weekly collections of approximately 50 alate aphids were collected at each location between 21 September and 4 November. In 1995, alate aphids alighting on winter wheat were collected at two central New York locations, Aurora and Ovid, and one western New York location, Albion. Approximately 50 alate aphids were collected at each location three to four times between 27 September and 6 November. In addition, aphids colonizing corn growing in Ithaca, NY, were collected in mid-September. Field-collected aphids were returned to the laboratory and individual aphids were allowed a 96-h inoculation access period (IAP) on healthy barley (cv. Lud) or oat (cv. Coast Black) seedlings. Aphids were subsequently identified to species, and the plants were fumigated with DDVP (0,0-dimethyl-0-[2,2-dichlorovinyl] phosphate) and grown under greenhouse conditions for 4 to 6 weeks. Plants were tested for BYDV or CYDV infection with a double-antibody sandwich, enzyme-linked immunosorbent assay (DAS-ELISA) (10). The antibodies that specifically detect each of the five viruses that can cause BYDV in New York were described previously $(35,46)$. A sample with an absorbance value $\left(A_{405}\right)$ three times higher than healthy was considered infected. BYDV-RMV isolates were maintained in 'Coast Black' oat in the greenhouse and routinely transferred to healthy oat plants using Rm-L. The BYDV-RMV field isolates had been transferred at least three times to healthy oat seedlings by Rm-L between the time of field collection and the start of the transmission experiments.

Aphid transmission assays. Leaf tissue from BYDV-RMVinfected plants (4 to 6 weeks postinoculation) was cut into 2- to 4-cm sections, randomly divided, and used as source tissue for aphid feeding. Unless otherwise stated, the source tissue was inoculated by Rm-L. Following a 48-h acquisition access period (AAP), 10 adult $R$. padi or Sitobion avenae, $10 R$. maidis nymphs, or 8 Schizaphis graminum nymphs were transferred to individual healthy oat seedlings for an IAP of $96 \mathrm{~h}$. The plants were fumigated, grown in a greenhouse for 2 to 6 weeks, and visually assessed for symptoms or tested by DAS-ELISA. Four to eight recipient plants were used in the transmission tests for each aphid clone-virus isolate combination. Tests were repeated three to five times over a 14-month period. The AAPs and IAPs were done at $16^{\circ} \mathrm{C}$ unless otherwise noted. Transmission efficiency was calculated as the number of infected plants divided by the total number of inoculated plants. To ensure that lack of transmission by an aphid was not due to low virus titer in the source tissue, the source tissue was collected after every transfer and tested by DASELISA. Results exclude tests where the source tissue had an absorbance value lower than three times healthy.

\section{RESULTS}

Virus isolates collected in the field. In 1994, 660 alate aphids were collected from winter wheat in Ithaca and Aurora, NY. Weather conditions at both locations were relatively mild, with mean daily temperatures between 18 to $22^{\circ} \mathrm{C}$ during the latter half of September, and no significant rainfall or frosts occurred during this time. A total of $505 R$. padi, 112 R. maidis, and 43 Sitobion avenae were tested for virus transmission. Relatively large populations of $R$. padi and $R$. maidis were observed colonizing corn at both locations. Sixty-two aphids transmitted virus to oat seedlings: $23 R$. padi, $11 R$. maidis, and two Sitobion avenae transmitted BYDV-PAV; five $R$. maidis and $19 R$. padi transmitted BYDV-RMV; and one $R$. padi transmitted both BYDV-PAV and BYDV-RMV. Similar numbers of each aphid were collected and transmitted virus from each location. All the BYDV-RMV field isolates reacted positively with BYDV-RMV-specific antiserum, but not with BYDV-PAV-specific or BYDV-RPV-specific antisera.

All but one of the BYDV-RMV field isolates induced mild symptoms on 'Coast Black' oats that were similar to those induced by BYDV-RMV-NY. One isolate induced severe stunting and chlorosis but, unfortunately, this isolate was not transmitted in subsequent transfers and was lost prior to further characterization. Nine BYDV-RMV isolates, seven initially transmitted by $R$. padi and two by $R$. maidis, were selected for further characterization.

In 1995, 457 aphids were collected from winter wheat in Aurora, Ovid, and Albion, NY. Mean daily temperatures during the later half of September were between 16 to $20^{\circ} \mathrm{C}$, but night temperatures were often below $10^{\circ} \mathrm{C}$; three frosts were recorded and rain was common. Aphid populations were noticeably lower on corn in 1995 than in 1994. A total of $162 R$. padi, $216 R$. maidis, and 79 Sitobion avenae were tested for virus transmission. Two $R$. maidis collected in Aurora transmitted BYDV-RMV, four $R$. maidis and one $R$. padi collected in Ovid transmitted BYDV-RMV, and $15 R$. maidis collected in Albion transmitted BYDV-RMV. Thirtyone apterous aphids $(31 \mathrm{R}$. padi, $18 \mathrm{R}$. maidis, and 50 Sitobion avenae) were collected from corn and winter rye in Ithaca, NY. Three Sitobion avenae collected from winter rye transmitted BYDV-RMV, and nine $R$. maidis collected from corn transmitted BYDV-RMV. The BYDV-RMV isolates were all transmitted from the initially infected oat plants to healthy 'Coast Black' oat plants with Rm-L; however, attempts to transfer the three BYDV-RMV isolates initially transmitted by Sitobion avenae using Sa-L failed, as did attempts to transfer the one isolate initially transmitted by $R$. padi using Rp-L. No further transmission tests were done with the BYDV-RMV isolates collected in 1995.

Transmission phenotype of the 1994 BYDV-RMV isolates. The transmission specificity of the nine field-collected BYDVRMV isolates was first compared with that of BYDV-RMV-NY using laboratory-maintained clones of $R$. maidis (Rm-L), $R$. padi (Rp-L), Schizaphis graminum (Sg-L), and Sitobion avenae (Sa-L) (Table 1). All of the isolates except RMV-46 were similar in that they were transmitted more efficiently by Rm-L than by Sg-L. However, the efficiencies varied among isolates, ranging from 40 to $94 \%$ for $\mathrm{Rm}-\mathrm{L}$ and 4 to $25 \%$ for $\mathrm{Sg}$-L. Isolate RMV-46 was inefficiently transmitted by both aphids. In these experiments, RpL transmitted only isolate RMV-184 and only to one plant. None of the isolates were transmitted by Sa-L.

To determine if there were differences among clones of the same aphid species to transmit BYDV-RMV isolates, transmission assays were conducted using the $R$. padi and $R$. maidis clones collected in 1993 to 1995 . The results are summarized in Table 2. The two $R$. maidis clones were similar in transmission efficiency for the BYDV-RMV isolates, with the exception of isolates RMV46 and RMV-56, which were not transmitted or were transmitted less efficiently, respectively, by the field population of $R$. maidis (Table 2). There were differences in the vectoring ability of the 
four $R$. padi clones. The Rp-L was consistently the least efficient vector, transmitting only RMV-NY and RMV-NY184. The Rp-A clone was similar to Rp-L, but occasionally transmitted RMVNY66 and RMV-NY110 in addition to RMV-NY and RMV-NY184. $\mathrm{Rp}-\mathrm{C}$ and $\mathrm{Rp}-\mathrm{W}$ were similar in their vectoring ability and consistently transmitted all the BYDV-RMV isolates tested, except RMV-NY119 and RMV-NY141, which were not transmitted by any $R$. padi clone (Table 2). It is important to note that RMV-NY119 and RMV-NY141 were the two isolates obtained from viruliferous $R$. maidis, whereas the other isolates were obtained from viruliferous $R$. padi.

During the investigation, over 250 plants were infested with $R$. padi (10 aphids per plant) that had previously fed on RMVNY141-infected plant tissue, yet no transmission occurred by any of the $R$. padi biotypes. The transmission of BYDV-RMV by $R$. padi and Sitobion avenae was temperature dependent (34). Therefore, an experiment was conducted to determine if the transmission of RMV-NY141 by $R$. padi would occur at higher temperatures. The Rp-C clone was unable to transmit RMV-NY141 when the AAP was $16^{\circ} \mathrm{C}$ ( 0 of 20 plants), but 10 of 20 plants became infected if the AAP was done at $25^{\circ} \mathrm{C}$. Similarly, the transmission of RMV-NY184 by Rp-C increased from 30 to $70 \%$ at 16 and

TABLE 1. Transmission of Barley yellow dwarf virus-RMV isolates collected in 1994 by four cereal aphids ${ }^{\mathrm{a}}$

\begin{tabular}{lccccc}
\hline Isolate & $N^{\mathrm{b}}$ & $\begin{array}{c}\text { Rhopalosiphum } \\
\text { maidis }\end{array}$ & $\begin{array}{c}\text { Rhopalosiphum } \\
\text { padi }\end{array}$ & $\begin{array}{c}\text { Schizaphis } \\
\text { graminum }\end{array}$ & $\begin{array}{c}\text { Sitobion } \\
\text { avenae }\end{array}$ \\
\hline RMV-46 & 3 & $2 / 20$ & $0 / 20$ & $3 / 20$ & $0 / 20$ \\
RMV-56 & 5 & $13 / 24$ & $0 / 24$ & $6 / 24$ & $0 / 24$ \\
RMV-66 & 4 & $13 / 24$ & $0 / 24$ & $1 / 24$ & $0 / 24$ \\
RMV-102 & 4 & $13 / 20$ & $0 / 19$ & $3 / 20$ & $0 / 20$ \\
RMV-110 & 4 & $12 / 20$ & $0 / 20$ & $3 / 20$ & $0 / 20$ \\
RMV-119 & 5 & $21 / 24$ & $0 / 24$ & $4 / 24$ & $0 / 24$ \\
RMV-126 & 3 & $8 / 20$ & $0 / 20$ & $2 / 20$ & $0 / 20$ \\
RMV-141 & 4 & $8 / 20$ & $0 / 20$ & $3 / 20$ & $0 / 20$ \\
RMV-184 & 5 & $16 / 24$ & $1 / 24$ & $6 / 24$ & $0 / 23$ \\
RMV-NY & 5 & $15 / 16$ & $0 / 20$ & $3 / 17$ & $0 / 17$ \\
Healthy & 5 & $0 / 22$ & $0 / 22$ & $0 / 22$ & $0 / 21$ \\
\hline
\end{tabular}

a Aphid clones were originally collected in the late 1950s and have been maintained in the laboratory (34). Numerator is the number of plants infected, denominator is the number of plants inoculated. This is a total for all experiments. Each plant was inoculated with 10 aphids that had previously been given a 48-h acquisition access period on infected tissue.

${ }^{\mathrm{b}}$ Indicates the number of independent experiments using four to eight plants per experiment.

TABLE 2. Transmission of Barley yellow dwarf virus-RMV isolates by multiple clones of Rhopalosiphum maidis and R. padi ${ }^{\text {a }}$

\begin{tabular}{lrrrrrrr}
\hline & \multicolumn{2}{c}{$R$. maidis } & & \multicolumn{4}{c}{ R. padi } \\
Isolate $^{\text {b }}$ & $\mathrm{Rm}-\mathrm{L}$ & $\mathrm{Rm}-\mathrm{A}$ & & $\mathrm{Rp}-\mathrm{L}$ & $\mathrm{Rp}-\mathrm{W}$ & $\mathrm{Rp}-\mathrm{C}$ & $\mathrm{Rp}-\mathrm{A}$ \\
\hline RMV-46 & $7 / 20$ & $0 / 16$ & & $0 / 20$ & $1 / 19$ & $5 / 20$ & $0 / 16$ \\
RMV-56 & $19 / 20$ & $4 / 16$ & & $0 / 20$ & $3 / 20$ & $1 / 20$ & $0 / 16$ \\
RMV-66 & $14 / 20$ & $16 / 16$ & & $0 / 20$ & $16 / 20$ & $4 / 20$ & $2 / 16$ \\
RMV-102 & $8 / 20$ & $12 / 16$ & & $0 / 20$ & $2 / 20$ & $3 / 20$ & $0 / 16$ \\
RMV-110 & $40 / 67$ & $29 / 52$ & & $0 / 82$ & $19 / 82$ & $14 / 82$ & $6 / 70$ \\
RMV-119 & $14 / 16$ & $8 / 8$ & & $0 / 20$ & $0 / 20$ & $0 / 20$ & $0 / 8$ \\
RMV-126 & $11 / 16$ & $8 / 16$ & & $0 / 20$ & $3 / 19$ & $3 / 20$ & $0 / 16$ \\
RMV-141 & $39 / 64$ & $24 / 58$ & & $0 / 63$ & $0 / 62$ & $0 / 64$ & $0 / 58$ \\
RMV-184 & $49 / 68$ & $32 / 58$ & & $4 / 71$ & $13 / 70$ & $21 / 71$ & $5 / 59$ \\
RMV-NY & $42 / 51$ & $33 / 43$ & & $1 / 54$ & $10 / 55$ & $11 / 54$ & $1 / 43$ \\
\hline
\end{tabular}

${ }^{a} \mathrm{Rm}-\mathrm{L}$ and Rp-L were collected in 1958 in Ithaca, NY, and in 1956 in Urbana, IL, respectively. Rp-W was collected from wheat in 1993 in Ithaca, NY. Rp-C was collected from corn in 1995 in Ithaca, NY. Rp-A and Rm-A were collected from corn in Albion, NY, in 1995. All were maintained on barley in the laboratory. Numerator is the number of infected plants, denominator is the number of plants inoculated (10 aphids per plant). These are the totals from two to nine independent experiments.

${ }^{\mathrm{b}}$ All virus isolates were originally obtained from viruliferous $R$. padi with the exception of RMV-119 and RMV-141, which were obtained from viruliferous $R$. maidis. $25^{\circ} \mathrm{C}$, respectively. The increased transmission of both of these isolates by $R$. padi was significant $(P<0.02)$.

Experiments were conducted to determine if the species of aphid that inoculated a plant had an effect on the transmission efficiency of different aphid species or clones that later used that plant as a virus source. Plants were inoculated with RMV-NY, RMV-NY110, or RMV-NY184 using Rm-L or Rp-C. These plants were later used as a virus source for $\mathrm{Rm}-\mathrm{L}$ and all of the $R$. padi clones described previously. Transmission by $R$. maidis was not significantly affected by the inoculating aphid (Fig. 1). Transmission of the BYDV-RMV isolates by the $R$. padi clones tested was higher when the source plant was inoculated by $R$. padi than when it was inoculated by $R$. maidis, although the increase was markedly different among isolate-aphid clone combinations (Fig. 1). The increase in transmission efficiency was especially dramatic for the RMV-NY184 isolate. The transmission efficiency of NY184 by $R$. padi feeding on plants inoculated by $R$. padi was two to five times higher than on plants inoculated by $R$. maidis. Similar to previous results, RMV-110 was not transmitted by Rp$\mathrm{L}$, regardless of which aphid species inoculated the plant.

\section{DISCUSSION}

This study provides supporting information on the epidemiology of BYDV in winter wheat in the northeastern United States $(7,8,39-41)$ and extends our knowledge on how genetic diversity within luteoviruses and their aphid vectors can impact the epidemiology of BYDV. A majority of the spread of virus into the New York winter wheat crop occurs in the fall by alate $R$. padi and $R$. maidis moving into the crop, many coming from the senescing corn crop. The seasonal phenology of migrating aphids is consistent from year to year, although the number of each species, relative to each other, can vary from year to year, evidenced by the differences between 1994 and 1995. R. maidis alates are abundant on wheat in September and October and a relatively high proportion (up to 49\%) transmit BYDV-RMV in any given year (8; this study), but $R$. maidis rarely colonizes the crop. $R$. padi alates are also abundant on wheat in September and October but, in contrast to $R$. maidis, apterous colonies are typically observed into November. $R$. padi will survive several heavy

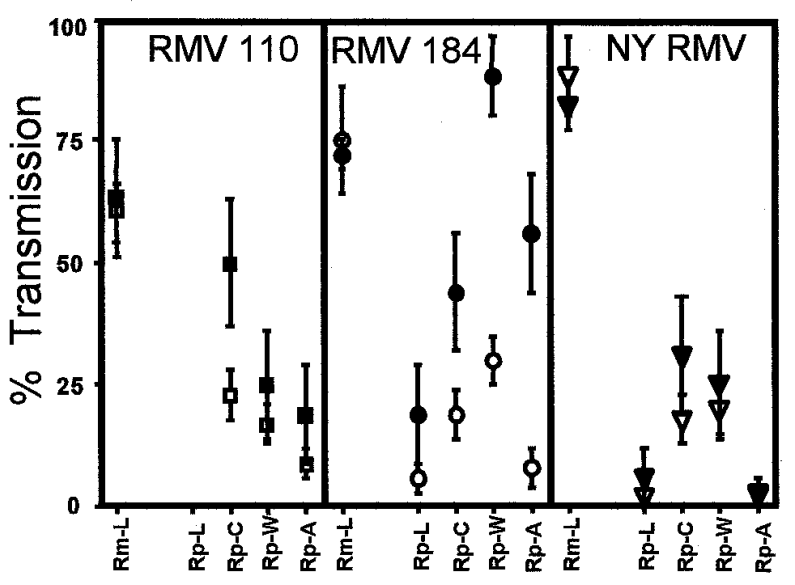

Fig. 1. The effect of the inoculating aphid on the transmission of three isolates of Barley yellow dwarf virus (BYDV)-RMV by the efficient vector, Rhopalosiphum maidis (Rm-L), and several clones of the inefficient vector, R. padi (Rp-L, Rp-C, Rp-W, and Rp-A). Virus source tissue used in the experiments was inoculated with RMV-110, RMV-184, or RMV-NY with either $\mathrm{Rm}-\mathrm{L}$ or Rp-L. Three to four weeks following inoculation, the various aphids were given a 48-h acquisition access period and transferred in groups of 10 to healthy oat seedlings. Mean transmission efficiency and standard errors, calculated as a proportion of plants infested per plants inoculated, are provided for three independent virus sources inoculated by Rm-L (open symbols) or Rp-L (filled symbols) for each aphid species/clone. 
frosts and light snows. The number of $R$. padi alates transmitting BYDV-RMV differed dramatically between 1994 and 1995, and this difference is likely to be a function of genetics and environment.

Genetic diversity abounds within $R$. maidis as evidenced by numerous biotypes differing in karyotype and morphology $(1,25)$. However, all $R$. maidis biotypes are efficient vectors of BYDVRMV (2,36; this study). Similarly, BYDV-RMV isolates are genetically diverse in coat protein sequence $(4,6)$, but all BYDVRMV isolates tested to date are most efficiently transmitted by $R$. maidis $(2,5,11,15,18,24,29,45)$. It seems likely that genetic diversity within $R$. maidis and BYDV-RMV does not extend to major changes in efficient vectoring ability, at least for BYDV-RMV. This genetic uniformity does not extend to Schizaphis graminum and $R$. padi, which vector BYDV-RMV but at a lesser efficiency than $R$. maidis $(2,15,34,45)$. Genetic diversity has been widely studied in Schizaphis graminum $(28,43)$ and $R$. padi $(14,22,44)$, and in contrast to $R$. maidis, there are considerable differences among clones of Schizaphis graminum and $R$. padi in the transmission efficiency of poleroviruses and luteoviruses, including BYDV-RMV (9,12-14,31). Thus, it is not appropriate to assume that the relative transmission efficiencies of BYDV or CYDV species is consistent across all or even most clonal populations of any aphid species.

The genetic diversity of aphids can definitely influence the epidemiology of BYDV, but the environment may also play an important role. The general finding that $R$. padi is a poor vector of BYDV-RMV is certainly influenced by the temperature at which the transmission tests are conducted. Lower temperatures reduce the transmission, whereas higher temperatures can increase dramatically the transmission efficiency (34; this study). The higher temperatures are often more reflective of conditions in the field. The unseasonably warm temperatures that prevailed in the later half of September 1994 undoubtedly provided a better environment for $R$. padi, the predominate aphid that year, to acquire BYDV-RMV from infected corn prior to migrating into the emerging winter wheat crop. A majority of the $R$. padi alates transmitting BYDV-RMV were collected at the end of September and the beginning of October. In contrast, in 1995, temperatures were colder during this same period, and the numbers of $R$. padi were lower than in 1994 and few transmitted BYDV-RMV. The high populations of $R$. padi that occur in many geographical areas, coupled with elevated temperatures, would allow $R$. padi to be a significant and efficacious vector of BYDV-RMV isolates in many cereal crops.

Further complicating the epidemiology of BYDV-RMV is the evidence that $R$. padi may be a more efficient vector of BYDVRMV if the plant was originally inoculated by $R$. padi. Others have examined the effect of the inoculating aphid on the subsequent acquisition of BYDV by various aphids and concluded that the inoculating aphid had no effect on subsequent transmissions $(27,32,33)$. However, in these cases, the infected plant was initially inoculated by a "nonvector," an event that occurs with low efficiency with most of the BYDV (CYDV)-aphid species combinations (26). Furthermore, there was no evidence that the virus transmitted by the nonvector was a variant in the population that could be consistently transmitted by the nonvector. The experiments reported here used an inefficient vector $(R$. padi) rather than a nonvector and inefficient transmission was consistent over time with some $R$. padi clones. Similar adaptation of BYDV-RMV, using the inefficient vector Schizaphis graminum, was reported $(16,17)$. It is likely that BYDV-RMV exists as a population of variants that differ in their ability to be transmitted by inefficient vectors such as $R$. padi and Schizaphis graminum. Passage of the virus through the inefficient vectors could select variants that are more efficiently transmitted in subsequent transmission events. Whether this would ultimately lead to an isolate of BYDV-RMV that is efficiently transmitted by $R$. padi is unknown. Also un- known is whether an increase in transmission efficiency by $R$. padi would lead to a decrease in efficiency by $R$. maidis, although our current data suggest that most, if not all, of the variants are efficiently transmitted by $R$. maidis. The aphid clone also will influence the adaptability of the virus transmission phenotype. Rochow and Jedlinski (37) conducted similar experiments as we describe using isolates of BYDV-RMV collected in Illinois and only the Rp-L aphid. They found no significant effect of the inoculating aphid on subsequent transmissions. Our results with the Rp-L clone were similar, although we did observe changes when other $R$. padi clones were used.

BYDV-RMV is one of the more diverse members of the Luteoviridae with respect to biological and molecular properties, and it appears to be a prevalent virus in the BYDV complex wherever wheat and corn crops overlap, e.g., northern United States and northern Europe. In general, BYDV-RMV is not considered to cause a significant disease problem, and symptoms are mild or absent. However, very little is known about its economic impact on production agriculture. Some BYDV-RMV isolates can significantly reduce yields in sweet corn (19), and the virus may have serious unrecognized impacts on other cereal crops. Clearly, the BYDV-RMV-NY isolate described by Rochow (34) does not represent the diversity of BYDV-RMV isolates in nature. Rochow stated that the BYDV-RMV serotype and its aphid transmission phenotype were the most variable of all the cereal-infecting luteoviruses $(34,37)$. The work reported here certainly supports Rochow's observations and it calls attention to the potential dangers of generalizing virus-vector relationships when investigating the epidemiology of BYDV.

\section{ACKNOWLEDGMENTS}

This research was supported in part by a SUNY Fellowship to E. Lucio-Zavaleta. We thank R. H. Vaughan for technical assistance.

\section{LITERATURE CITED}

1. Blackman, R. L., Halbert, S. E., and Carroll, T. W. 1990. Association between karyotype and host plant in corn leaf aphid in the northwestern USA. Environ. Entomol. 19:609-611.

2. Brumfield, S. K. Z., Carroll, T. W., and Gray, S. M. 1992. Biological and serological characterization of three Montana RMV-like isolates of barley yellow dwarf virus. Plant Dis. 76:33-39.

3. Cheng, Z., He, X., Wu, M., Zhou, G., Keese, P., and Waterhouse, P. M. 1996. Nucleotide sequence of coat protein gene for GPV isolate of barley yellow dwarf virus and construction of expression plasmid for plant. Sci. China Ser. C Life Sci. 39:534-543.

4. Domier, L. L., Lukasheva, L. I., and D’Arcy, C. J. 1994. Coat protein sequences of RMV-like strains of barley yellow dwarf virus separate them from other luteoviruses. Intervirology 37:2-5.

5. Farrel, J. A., and Sward, R. J. 1989. Barley yellow dwarf virus serotypes and their vectors in Canterbury New Zealand. Aust. Plant Pathol. 18:21-23.

6. Geske, S. M., French, R., Robertson, N. L., and Carroll, T. W. 1996. Purification and coat protein gene sequence of a Montana RMV-like isolate of barley yellow dwarf virus. Arch. Virol. 141:541-556.

7. Gildow, F. E., Frank, J., Bingaman, D., and Powell, C. 1987. Barley yellow dwarf viruses in small grains in Pennsylvania: Isolate identification, distribution, and vector efficiency. Plant Dis. 71:922-926.

8. Gray, S. M., Bergstrom, G. C., Vaughan, R., Smith, D. M., and Kalb, D. W. 1996. Insecticidal control of cereal aphids and its impact on the epidemiology of the barley yellow dwarf luteoviruses. Crop Prot. 15:687-697.

9. Gray, S. M., Chapin, J. W., Smith, D. M., Banerjee, N., and Thomas, J. S. 1998. Barley yellow dwarf luteoviruses and their predominant aphid vectors in winter wheat grown in South Carolina. Plant Dis. 82:13281333.

10. Gray, S. M., Smith, D., and Altman, N. 1993. Barley yellow dwarf virus isolate-specific resistance in spring oats reduced virus accumulation and aphid transmission. Phytopathology 83:716-720.

11. Greber, R. S. 1989. Ecology of barley yellow dwarf viruses in southeast Queensland Australia. Aust. Plant Pathol. 17:101-104.

12. Guo, J.-Q., Lapierre, H., and Moreau, J.-P. 1997. Clonal variations of virus regulation by aphids in transmission of a French PAV-type isolate 
of barley yellow dwarf virus. Plant Dis. 81:570-575.

13. Guo, J. Q., Moreau, J. P., and Lapierre, H. 1996. Variability among aphid clones of Rhopalosiphum padi L. and Sitobion avenae Fabr. in transmission of three PAV isolates of barley yellow dwarf viruses. Can. Entomol. 128:209-217.

14. Habekuss, A., Leistner, H. U., and Schliephake, E. 1999. Characterization of Rhopalosiphum padi genotypes differing in the geographical origin by transmission efficiency of barley yellow dwarf viruses and molecular markers. Phytopathol. Z. 106:437-443.

15. Halbert, S. E., Connelly, B. J., Lister, R. M., Klein, R. E., and Bishop, G. W. 1992. Vector specificity of barley yellow dwarf virus serotypes and variants in southwestern Idaho. Ann. Appl. Biol. 121:123-132.

16. Hazelwood, D., Gray, S. M., and Carroll, T. W. 1990. Selection of RMVlike isolates of barley yellow dwarf virus efficiently transmitted by Schizaphis graminum. (Abstr.) Phytopathology 80(suppl.):S1022.

17. Hazelwood, D., Gray, S. M., and Carroll, T. W. 1992. Variation in long term stability of aphid transmission phenotype of RMV isolates of barley yellow dwarf virus. (Abstr.) Phytopathology 82(suppl.):S1090.

18. Helmke, C., and Huth, W. 1996. Barley yellow dwarf virus - evidence and occurrence of the RMV-like strain in Germany. Phytopathol. Z. 103: 113-119.

19. Itnyre, R. L. C., D’Arcy, C. J., Pedersen, W. L., and Sweets, L. E. 1999. Reaction of sweet corn to inoculation with barley yellow dwarf virus RMV-IL. Plant Dis. 83:566-568.

20. Lister, R. M., and Ranieri, R. 1995. Distribution and economic importance of barley yellow dwarf. Pages 29-53.in: Barley Yellow Dwarf: 40 Years of Progress. C. J. D'Arcy and P. A. Burnett, eds., The American Phytopathological Society, St. Paul, MN.

21. Lister, R. M., and Rochow, W. F. 1979. Detection of barley yellow dwarf virus by enzyme-linked immunosorbent assay. Phytopathology 69: 649-654.

22. Martinez, T. D., Moya, A., Hebert, P. D. N., and Simon, J. C. 1997. Geographic distribution and seasonal variation of mitochondrial DNA haplotypes in the aphid Rhopalosiphum padi. Bull. Entomol. Res. 87:161-167.

23. Mayo, M. A. 1999. Developments in plant virus taxonomy since the publication of the 6th ICTV Report. Arch. Virol. 144:1659-1666.

24. Osler, R., Loi, N., and Pertot, I. 1992. Characterization of a RMV-like strain of BYDV by aphid transmission. Riv. Patol. Veg. 2:33-38.

25. Painter, R. H., and Pathak, M. D. 1960. The distinguishing features and significance of the four biotypes of the corn leaf aphid, Rhopalosiphum maidis. Proc. Int. Congr. Entomol., 11th.

26. Power, A. G., and Gray, S. M. 1995. Aphid transmission of barley yellow dwarf viruses: Interactions between viruses, vectors, and host plants. Pages 259-291 in: Barley Yellow Dwarf: 40 Years of Progress. C. J. D'Arcy and P. A. Burnett, eds. The American Phytopathological Society, St. Paul, MN.

27. Price, R. D., Muller, I., and Rochow, W. F. 1971. Variation in transmission of an isolate of barley yellow dwarf virus by Rhopalosiphum padi. Phytopathology 61:753-754.

28. Puterka, G. J., and Peters, D. C. 1995. Genetics of greenbug (Homoptera: Aphididae) virulence to resistance in sorghum. J. Econ. Entomol. 88: 421-429.
29. Ranieri, R., Van, O. B., and Lister, R. M. 1993. Vector relationships of four barley yellow dwarf virus Mexican isolates and four species of cereal aphids found commonly in the Valley of Mexico. Southwest. Entomol. 18:163-167.

30. Robertson, N. L., French, R., and Gray, S. M. 1991. Use of groupspecific primers and the polymerase chain reaction for the detection and identification of luteoviruses. J. Gen. Virol. 72:1473-1478.

31. Rochow, W. F. 1960. Specialization among greenbugs in the transmission of barley yellow dwarf virus. Phytopathology 50:881-884.

32. Rochow, W. F. 1961. A strain of barley yellow dwarf virus transmitted specifically by the corn leaf aphid. Phytopathology 51:809-810.

33. Rochow, W. F. 1963. Variation within and among aphid vectors of plant viruses. Ann. N.Y. Acad. Sci. 105:713-729.

34. Rochow, W. F. 1969. Biological properties of four isolates of barley yellow dwarf virus. Phytopathology 59:1580-1589.

35. Rochow, W. F., and Carmichael, L. E. 1979. Specificity among barley yellow dwarf viruses in enzyme immunosorbent assays. Virology 95: 415-420.

36. Rochow, W. F., and Eastop, V. F. 1966. Variation within Rhopalosiphum padi and transmission of barley yellow dwarf virus by clones of four aphid species. Virology 30:286-296.

37. Rochow, W. F., and Jedlinski, H. 1970. Variants of barley yellow dwarf virus collected in New York and Illinois. Phytopathology 60:1030-1035.

38. Rochow, W. F., and Muller, I. 1971. A fifth variant of barley yellow dwarf virus in New York. Plant Dis. 55:874-877.

39. Rochow, W. F., and Muller, I. 1974. Mixed infections of barley yellow dwarf virus isolates in winter grains. Plant Dis. 58:472-475.

40. Rochow, W. F., and Muller, I. 1976. Gradual change in predominating isolates of barley yellow dwarf virus in New York. Plant Dis. 60:387390.

41. Rochow, W. F., Muller, I., Tufford, L. A., and Smith, D. M. 1986. Identification of luteoviruses of small grains from 1981 through 1984 by two methods. Plant Dis. 70:461-464.

42. Saksena, K. N., Singh, S. R., and Sill, W. H. 1964. Transmission of barley yellow dwarf virus by four biotypes of the corn leaf aphid, Rhopalosiphum maidis. J. Econ. Entomol. 57:569-571.

43. Shufran, K. A., Peters, D. C., and Webster, J. A. 1997. Generation of clonal diversity by sexual reproduction in the greenbug, Schizaphis graminum. Insect Mol. Biol. 6:203-209.

44. Simon, J. C., Leterme, N., and Latorre, A. 1999. Molecular markers linked to breeding system differences in segregating and natural populations of the cereal aphid Rhopalosiphum padi L. Mol. Ecol. 8:965-973.

45. Sward, R. J., and Lister, R. M. 1988. The identity of barley yellow dwarf virus isolates in cereals and grasses from mainland Australia. Aust. J. Agric. Res. 39:375-384.

46. Webby, G. N., and Lister, R. M. 1992. Purification of the NY-RMV and NY-SGV isolates of barley yellow dwarf virus and the production and properties of their antibodies. Plant Dis. 76:1125-1132.

47. Yount, D. J., and Carroll, T. W. 1983. Barley yellow dwarf luteoviruses in Montana cereals. Plant Dis. 67:1217-1222.

48. Zhang, J. F., Zhao, Y. X., Yang, Y., Jing, X. Z., and Zhu, X. S. 1992. Preliminary study on yellow dwarf of corn infected by BYDV. Virol. Sin. 7:192-196. 